\title{
Asediar la fortaleza sin ánimo de conquista. La incidencia política de la sociedad civil en Habermas
}

\author{
Álvaro Ramis Olivos \\ Programa de doctorado en Ética y Democracia, Universitat de València. \\ Email: alrao@alumni.uv.es
}

\begin{abstract}
Resumen: El objeto de este trabajo es analizar el concepto de la sociedad civil presentado por Jürgen Habermas y su lugar en el contexto de los debates sobre la teoría democrática. Se introducirá el concepto de democracia deliberativa, haciendo hincapié en su relación con la noción de comunicación y opinión pública. De acuerdo a esta perspectiva la capacidad de la sociedad civil para influir en el campo público-político puede tender un puente entre las concepciones de la democracia de raíz liberal y las de raíz republicana.
\end{abstract}

Palabras clave: Sociedad civil, democracia deliberativa, incidencia política, desobediencia civil.

\section{Besieging the fortress with a non-conquest approach. Advocacy of civil society in Habermas}

Abstract: The purpose of this paper is to analyze the concept of civil society presented by Jürgen Habermas and his place in the context of discussions on democratic theory. It will introduce the concept of deliberative democracy, emphasizing its relation to the notion of communication and public opinion. According to this perspective, civil society capacity to influence the public-political field can bridge between the concepts of liberal and republican democracy.

Key words: Civil society, deliberative democracy, political advocacy, civil disobedience.

\section{Cercar a fortaleza não em conquista. Advocacia da sociedade civil em Habermas}

Resumo: O objetivo deste trabalho é analisar o conceito de sociedade civil, apresentada por Jürgen Habermas e seu lugar no contexto das discussões sobre a teoria democrática. Ele vai introduzir o conceito de democracia deliberativa, enfatizando sua relação com a noção de comunicação ea opinião pública. De acordo com esta perspectiva, a capacidade da sociedade civil para influenciar o campo público-político pode fazer a ponte entre os conceitos de democracia liberal e republicana.

Palavras-chave: sociedade civil, democracia deliberativa, a advocacia, a desobediência civil. 
Las relaciones entre sociedad política y sociedad civil son objeto de permanente debate y controversia. Tras esta discusión se advierte la existencia de diferentes concepciones normativas de la democracia que a su vez se sustentan en distintas interpretaciones de lo público y lo privado, de lo pertinente a la administración estatal y lo propio del mercado. En este dilema el concepto de sociedad civil adquiere un cariz especialmente problemático ya que ha adoptado diversos significados a lo largo de la historia.

Como consecuencia de esta oscilación conceptual, se fluctúa entre discursos políticos que otorgan a la sociedad civil atributos esenciales para la gobernabilidad democrática, la solución a los problemas de cohesión social y la resolución pacífica de las controversias y por otra se le califica como un campo opaco, caótico, irreductiblemente inmaduro, que debe ser conducido por la sociedad política.

En la actualidad la definición más habitual de sociedad civil coincide con la opinión de Jürgen Habermas, que la entiende como el ámbito de las relaciones no económicas y no estatales, donde sólo se admite la solidaridad derivada de la acción comunicativa como mecanismo de coordinación de la acción. Esta perspectiva coincide, por ejemplo, con el concepto que nos entrega el foro abierto sobre eficacia de las organizaciones de la sociedad civil:

"Las Organizaciones de la Sociedad Civil, OSC, son una característica viva y esencial en la vida democrática de los países a lo largo y ancho del mundo. Las OSC colaboran con una amplia diversidad de personas y promueven sus derechos. Como actores del desarrollo, se caracterizan por ser voluntarias, diversas, no-partidistas, autónomas, no-violentas, y trabajan por el cambio"1.

A su vez esta caracterización entronca con una tradición que orienta este concepto hacia un campo de organizaciones voluntarias que impulsan acciones de reforma social y contraloría del poder establecido. Es una perspectiva que sintoniza con autores clásicos como Alexis de Tocqueville, quién sostiene:

"no hay país en el que las asociaciones civiles sean más necesarias para impedir el despotismo de los partidos o la arbitrariedad del príncipe que aquél donde el estado social sea democrático. En las naciones aristocráticas, los cuerpos secundarios forman asociaciones naturales que frenan los abusos del poder. En los países donde no existen semejantes asociaciones, si los particulares no pueden crear artificialmente algo que se les parezca, no veo ya más diques a ninguna clase de tiranía, y un gran pueblo puede ser impunemente oprimido por un puñado de facciosos o por un solo hombre"”.

Sin embargo, la perspectiva que expresan Tocqueville y Habermas no deja de ser problemática. Michael Edwards ha reflexionado sobre el límite de esa concepción, que a su juicio: 
“cree que las asociaciones de voluntarios actúan como portadores del gen de la buena sociedad - microclimas, si se quiere, para el desarrollo de valores como la tolerancia y la cooperación, y las habilidades necesarias para vivir una vida democrática. El problema es que la vida asociativa real es el hogar de todo tipo de valores diferentes y en competencia y las creencias...por eso que la sociedad civil, en palabras del escritor británico John Keane «está plagado de peligros, ya que da libertad a los déspotas y demócratas por igual." 3

Por este motivo Edwards se muestra escéptico ante el concepto sociedad civil ya que parece encubrir más que revelar: "Por desgracia, la claridad y el rigor brilla por su ausencia en el debate de la sociedad civil, la falta de precisión que amenaza con sumergir este concepto completamente bajo una ola creciente de críticas y confusión”, por lo cual alerta sobre la tendencia a hacer de este concepto "la sopa de pollo de las ciencias sociales".

Domingo García-Marzá realiza una aguda observación crítica a la definición habermasiana de sociedad civil argumentando su carácter restringido a las relaciones no económicas y no estatales. Propone como alternativa una concepción radical de sociedad civil que dé cuenta del carácter global pero también plural de sus instituciones desde una perspectiva que busque superar la tradicional exclusión de las instituciones económicas del ámbito de la sociedad civil. De esa manera la teoría de la democracia no perdería uno de sus pilares básicos, pues incluiría “aquellos ámbitos de acción en los que de hecho se establecen la gran mayoría de las relaciones sociales y se produce y reproduce el poder económico y social.”4 De esa manera la definición de sociedad civil que propone es la siguiente:

“Ámbito de interacciones estructurado en torno a una red de asociaciones y organizaciones posibles gracias al libre acuerdo de todos los participantes, con el fin de alcanzar conjuntamente la satisfacción de determinados intereses y la resolución consensual de posibles conflictos de acción”5

La perspectiva de García-Marzá supone que "En los ámbitos de la sociedad civil nos encontramos con intereses particulares (prestigio, dinero, etc.), pero también podemos encontrarnos con intereses comunes (profesionales, corporativos, etc.) y con intereses generales o universales (reconocimiento, dignidad, etc.). También en esta concepción de la sociedad civil, el ámbito moral se identifica con los intereses generalizables, pero no se encierra en sí mismo como el caso de Habermas”6 .

La definición de García Marzá coincidiría más con un enfoque que encuentra fundamento en Hegel, quién caracteriza a la sociedad civil como un campo de relaciones situado entre un ámbito estrictamente privado (la familia) y otro estrictamente público (el Estado). Se trataría de una esfera en la cual cada individuo persigue de forma egoísta sus propios intereses, pero las necesidades propias de esos objetivos le exigen del vínculo con- 
tractual, lo que explica la trama de interdependencias propia de la vida en sociedad. Sin embargo, en las relaciones de la sociedad civil siempre primarán los deseos privados y personales, las demandas corporativistas, los intereses sectoriales. Para Hegel, solo el ámbito del Estado permite la superación de este aislamiento individual, universalizando los deseos, y convirtiéndolos en leyes. Por este motivo, Hegel sitúa al Estado por sobre la sociedad civil y los grupos intermedios (familias y corporaciones), entendiéndolo como la verdadera realización de la libertad objetiva sobre la tierra:

"La sociedad civil es la diferencia que se coloca entre la familia y el Estado, aunque el perfeccionamiento de ella se sigue más tarde que el del Estado, ya que la diferencia presupone al Estado, al cual ella, para subsistir, tiene que tener ante si como autónomo. La creación de la sociedad civil pertenece por lo demás, al mundo moderno, el cual sólo deja que hagan su derecho a todas las determinaciones de la idea"7

Mientras para la tradición Tocqueviliana la sociedad civil es fundamentalmente un ámbito asociativo con vocación pública, en clara diferencia de los mecanismos productivos y distributivos del sistema económico, para Hegel la sociedad civil es todo lo no estatal, incluyendo el mercado. Esta somera descripción explica que el concepto de sociedad civil transite pendularmente entre estos dos polos. Mientras un ámbito de autores tiende a asignar a la sociedad civil un rol basado en sus supuestas cualidades inherentes, ya sea como fuente de solidaridad o como baluarte de libertades y derechos, por otro lado se le suele desdeñar como un ámbito de intereses dispersos, contradictorios y difícilmente articulables,. Entre ambos polos opera una diferencia de contenidos.

\section{La sociedad civil en el marco de la teoría de la acción comunicativa}

Es necesario asumir que la concepción de sociedad civil de J. Habermas es restringida, por lo que corre el riesgo de acabar siendo meramente desiderativa o utópica ya que no responde al hecho que "todas las instituciones, incluidas las empresas, son más o menos justas, más o menos correctas o morales”", tal como señala García Marzá.

Por otra parte, el concepto de sociedad civil que propone Jürgen Habermas, aunque no permite dar cuenta de la sociedad civil en toda su extensión y radicalidad, sigue siendo de gran relevancia, en la medida en que permite una interpretación de aquella esfera pública no estatal y no económica a la cual se refiere específicamente en su obra. Ese campo si bien no se debería identificar en strictu sensu con "la" sociedad civil, es una dimensión que no deja de existir y que Habermas releva, dando importancia a su capacidad de incidencia política, rescatándola de su posible fetichización, bajo la panacea de la “gran sociedad”, en la línea argumental 
de quienes justifican la reducción del rol del Estado bajo la excusa de incrementar el rol del voluntariado asociativo.

Más que un rol subsidiario, la concepción habermasiana de "sociedad civil" como esfera asociativa no lucrativa, adquiere un rol autónomo que le permite influir en la política desde el ámbito de la opinión pública: «La sociedad civil se compone de esas asociaciones, organizaciones y movimientos surgidos de forma más o menos espontánea que recogen la resonancia de los ámbitos de la vida privada, la condensa y elevándole, por así decir, el volumen o voz, la transmiten al espacio de la opinión pública política”9 .

Esta valorización del campo no estatal y no económico, entendido como poder comunicativo, se inscribe en un intento de recuperar el proyecto de la teoría crítica y de la modernidad ilustrada, abandonando el paradigma de razón instrumental. Bajo este supuesto se diagnostica que la modernidad ha abusado de una noción de razón que se ha centrado exclusivamente en aquellas acciones estratégicas orientadas hacia el éxito, según una lógica instrumental. Sin embargo también es posible dar cuenta de otra racionalidad, la comunicativa, que opera como un conjunto de pretensiones de validez presentes en todo agente que actúa lingüísticamente con vistas a entenderse con otros. De esta forma la razón podría escapar de la esfera estrictamente individual y situarse esfera dialógica de la cooperación entre sujetos.

Esa segunda racionalidad, de carácter comunicativo, no comprende a la sociedad como el campo de la consecución de fines estratégicos individuales, sino como un ámbito de actores, que aspiran a coordinarse a través de actos de entendimiento, haciendo posible su reconocimiento recíproco. En otras palabras, la sociedad se puede conceptualizar tanto bajo una lógica instrumental, como bajo una lógica comunicativa, que la entiende como un conjunto activo de individuos que cooperativamente buscan reproducir, mantener y mejorar sus condiciones de vida.

Estas dos racionalidades, la instrumental y la comunicativa, se integran en una doble dimensión que Habermas denomina «sistema» y «mundo de la vida”. Por sistema se refiere a la acción coordinada dirigida a fines, mientras que por mundo de la vida al ámbito de integración intersubjetiva. El sistema es una dimensión funcional observable y describible mediante el que los miembros de una sociedad desarrollan su acción guiados por criterios racionales adecuados al control de sus circunstancias vitales. En él opera una «integración sistémica» que permite el desarrollo material de la vida en sociedad. En cambio, el mundo de la vida es el ámbito de la integración intersubjetiva, de aquellas estructuras comunicativas mediante las cuales se establecen los acuerdos básicos que rigen la pertenencia y cooperación en el sistema. Es el trasfondo valórico, normativo, de tradiciones culturales y patrones de socialización que reconocidos como válidos permiten la interacción comunicativa y la integración de los individuos. 
La modernidad, como proceso de secularización y desencantamiento del mundo, rompió el vínculo entre ambas dimensiones dejo de operar como lo hacía en las sociedades premodernas. Se produjo una autonomización del sistema que obligó a implementar mecanismos de control propios de la racionalidad instrumental: el poder se focalizó en el campo político y el mercado pasó a autorregularse exclusivamente por las dinámicas internas del capital. El control social o religioso fue sustituido por reglas racionalmente acordadas, que permitieron el desarrollo de la racionalización económico-burocrática de los fenómenos sociales. A su vez el propio mundo de la vida también se racionalizó, adquiriendo reflexividad crítica. De esa forma la moral dejó de responder a la tradición y las instituciones reemplazaron los principios teológicos de legitimación por el principio de autonomía y por procedimientos legislativos basados en el pacto político.

En este nuevo marco, la democracia podría haber sido un medio privilegiado para revincular sistema y mundo de la vida por medio de procedimientos deliberativos que colaboraran a superar la cosificación de las relaciones intersubjetivas por medio del acuerdo comunicativo entre personas libres e iguales. Sin embargo, la democracia tal como la conocemos, no ha logrado este objetivo ya que ella misma se ha hecho presa de la lógica del dominio propia de la razón instrumental. La sociedad civil, en cuanto ámbito de la racionalidad comunicativa, quedó aislada en el mundo de la vida, mientras la sociedad política se convirtió en instrumento de control tecnocrático, basado en la lógica de la funcionalidad utilitaria, que coloniza internamente al propio mundo de la vida por medio de lógicas monetarizadoras y burocráticas.

Desde una racionalidad no instrumental Habermas propone revisar el ámbito propio de la racionalidad comunicativa para dar espacio a un modelo de democracia deliberativa que supere a las democracias en sus versiones liberales y republicanas, pero que a la vez se sustente en los elementos básicos de ambas.

\section{Democracia Liberal, democracia republicana y democracia deliberativa}

La concepción liberal de la democracia otorga una serie de derechos a los individuos, tratando de garantizar su "libertad negativa", es decir, la no interferencia del Estado en sus intereses. Los individuos programan al Estado en las elecciones y después se retiran al ámbito de lo privado. En este esquema los actores de la política están altamente profesionalizados y se expresan en los partidos, entendidos como instituciones especializadas, que compiten en un "mercado" electoral. Entre el Estado y la sociedad civil existiría una brecha infranqueable, que sólo se puede amortiguar por mecanismos institucionales de contraloría institucional que eviten la personalización del poder.

Frente a esta concepción liberal, es posible adscribir a un modelo republicano de democracia, que más allá de garantizar las “libertades nega- 
tivas" permita ejercer las "libertades positivas", es decir, el derecho a la participación activa, constante y profunda en los procesos de deliberación pública. La democracia se entiende así como la autodeterminación de los sujetos, ejercida en un marco de diálogo racional. En este contexto los partidos políticos y la ciudadanía adquieren otro carácter. Jürgen Habermas, analizando este contraste, afirma que "según la concepción republicana el proceso de formación de la opinión y la voluntad política en el espacio público y en el parlamento no obedece a las estructuras de los procesos de mercado sino a las estructuras propias de una comunicación política orientada al entendimiento" ${ }^{10}$.

Se trata de una concepción de la democracia que atestigua con Hahnna Arendt que "Nadie puede ser feliz sin participar en la felicidad pública, nadie puede ser libre sin la experiencia de la libertad pública, y nadie, finalmente, puede ser feliz o libre sin implicarse y formar parte del poder político" ${ }^{\prime 11}$. Concepción que entronca muy claramente con la tradición Tocquevilliana.

Si se analiza la concepción liberal de la soberanía popular se entenderán las elecciones como una forma de legitimar el ejercicio del poder político. Una vez que se ha accedido al poder de forma legítima, en elecciones justas, el representante sólo debe responder por el uso que hace de ese poder en el marco de las atribuciones que la da la ley. Esta concepción corre el riesgo constante de vivir una crisis de legitimidad y una pérdida de sentido ya que se reduce a un procedimiento estratégico orientado exclusivamente a alcanzar el poder. En cambio, la concepción republicana considera que el acto electoral no sólo habilita a ejercer un mandato, sino que compromete a cumplir un programa que se ha construido mediante el acuerdo de un conjunto de actores implicados. Cualquier cambio en ese programa implica un proceso de rendición de cuentas a los ciudadanos que han validado ese programa. Una democracia republicana exigiría garantizar institucionalmente diversos espacios públicos autónomos y procedimientos de formación de la opinión y la voluntad ciudadana que se puedan sostener autónomamente frente al poder del sistema económico y al poder del Estado.

La debilidad de la concepción republicana radica en el voluntarismo que supone aspirar a una ciudadanía constantemente participativa, capaz de predeterminar una voluntad general. En ese punto la tradición republicana no da cuenta de la complejidad y diferenciación social y cultural de las sociedades contemporáneas. Por su parte la crítica liberal al republicanismo democrático lo encarna Isaiah Berlin quién considera que en el nombre de la libertad positiva se busca limitar la libertad negativa. A su juicio la «verdadera» libertad no ha servido para otra cosa que para violar la libertad fáctica, con el falaz argumento de «obligar al hombre a ser verdaderamente libre» ${ }^{12}$.

Estas dos concepciones de la democracia poseen muy distintas formas de plantear las relaciones entre el Estado y la sociedad civil, que pue- 
den ir desde un modelo monológico de acción política a un modelo dialógico, donde la ciudadanía sea capaz de incidir en las decisiones políticas, orientándolas en una determinada dirección, sin por ello subsumirse en su institucionalidad ni perder su autonomía. Habermas propone un modelo de democracia deliberativa en la cual la construcción de la legitimidad política sea el resultado de procesos constantes comunicativos racionales en el espacio público, de los que surgen consensos basados en intereses universalizables.

En consonancia a la intuición de Arendt respecto a que "el poder surge entre los hombres cuando actúan juntos y desaparece en el momento en que se dispersan." ${ }^{13}$ Habermas sostiene que un proceso deliberativo, si los individuos se comunican en igualdad de condiciones y libremente, es posible que el poder se constituya comunicativamente y no sólo estratégicamente. Para ello se requieren condiciones que garanticen la exclusión de coacciones, permitiendo la formulación de argumentos y la formación de la libre voluntad. Se pasa a considerar que los intereses universales surgen del espacio público-deliberativo en el cual los diversos actores argumentan en las condiciones de validez propias de una comunidad ideal de comunicación (inteligibilidad, verdad, veracidad y corrección normativa).

\section{Sociedad Civil y democracia deliberativa}

Habermas en el capitulo VIII de Facticidad y Validez presenta la idea de una democracia deliberativa, en la que sociedad civil y opinión pública adquieren un papel normativo, complementario y crítico. Ambos conceptos se sitúan en una confrontación ante el poder social del mercado y la burocracia estatal. En este esquema la opinión pública es un espacio público-político que estructura una sociedad civil enraizada en el mundo de la vida, que logra consistencia por medio de una trama comunicacional. Habermas define la opinión pública como un fenómeno o un espacio en red:

"una red para la comunicación de contenidos y tomas de postura, es decir, de opiniones, y en él los flujos de comunicación quedan filtrados y sintetizados de tal suerte que se condensan en opiniones públicas agavilladas en torno a temas específicos. Al igual que el mundo la vida en su totalidad, también el espacio de la opinión pública se reproduce a través de la acción comunicativa, para la que basta con dominar el lenguaje natural; y se ajusta a la inteligibilidad general de la práctica comunicativa cotidiana”14.

A su vez la sociedad civil, es entendida por Habermas como las asociaciones y organizaciones voluntarias, no estatales y no económicas, que surgen de forma más o menos espontánea, y que arraigan las estructuras comunicativas de la opinión pública en el mundo de la vida, ya que recogen las resonancias de los problemas en los ámbitos de la vida privada y elevándoles la voz, los transmiten al espacio de la opinión pública política: 
"esa trama asociativa no-estatal y no-económica, de base voluntaria, que ancla las estructuras comunicativas del espacio de la opinión pública en la componente del mundo de la vida, que -junto con la cultura y con la personalidad- es la sociedad.”15

La sociedad civil es el ámbito donde el poder se constituye comunicativamente y desde él se resiste el poder social del mercado y de la burocracia estatal. De esa forma Habermas perfila a la sociedad civil como ciudadanía organizada, que incide en la formación institucionalizada de la opinión y la voluntad política desde su propio ámbito privado, aportando interpretaciones de lo público desde fuera del poder administrativo y de los procesos económicos. Esta caracterización presupone el respeto a la autonomía y a la esfera privada de la sociedad civil por parte del Estado. La democracia deliberativa requiere que la sociedad civil sea protegida jurídicamente de modo que pueda cercar comunicativamente al poder administrativo del Estado, ejerciendo el rol de caja de resonancia de aquellos argumentos que han de ser procesados por el sistema político.

Este espacio público-político "es un sistema de avisos con sensores no especializados, pero que despliegan su capacidad perceptiva a lo largo y ancho de toda la sociedad. Desde el punto de vista de la teoría de la democracia el espacio público-político tiene que reforzar además la presión ejercida por los problemas, es decir, no solamente percibir e identificar los problemas, sino también tematizarlos de forma convincente y de modo influyente, proveerlos de contribuciones, comentarios e interpretaciones, y dramatizarlos de suerte que puedan ser asumidos y elaborados por el complejo parlamentario. Es decir, a cada función de señal del espacio públicopolítico ha de sumarse también una capacidad de problematización eficaz."16

En esta concepción se comprende el proceso legislativo y al derecho como un medio por el cual el poder comunicativo faculta y legitima al poder administrativo, haciendo a este último una expresión del primero. Siempre existirá la posibilidad que él "poder social" (para Habermas los poderes fácticos o privilegiados) ejerza una intervención ilegítima en la generación de las normas jurídicas. El uso estratégico del poder no se puede proscribir. Pero la legitimidad en un Estado de derecho exige un vínculo entre el poder comunicativo, entendido como fuente del derecho, y el poder administrativo, que regido por el código del poder, debe mantenerse fuera de las interferencias del poder social. Desde esa perspectiva la función normativa de la democracia no puede provenir de las elites burocráticas, sino de la sociedad civil

\section{Formas de incidencia de la sociedad civil en el espacio público-político}

Habermas analiza cómo la sociedad civil ejercita este proceso de incidencia en el espacio político. Señala que la opinión pública expresa 
problemas relevantes de la sociedad que ponen en riesgo su integración. Estos problemas muestran la insuficiencia de las normas, valores y formas rutinarias de entendimiento, lo que obliga a la política y al derecho a asumir un rol en la resolución de estas demandas.

El proceso deliberativo opera a través de un "centro" conformado por todos los órganos e instituciones de la Administración del Estado. Allí se procesan rutinariamente las decisiones por medio de lo que Habermas denomina, siguiendo a Bernhard Peters, un sistema de "esclusas" constituido por un complejo sistema que comunica a los diversos órganos gubernamentales entre sí. Junto a este "centro" existe una "periferia interna" que vendría a ser el conjunto de las instituciones delegadas por el Estado, con cierta autonomía administrativa, para ejercer roles de competencia y control estatal. Entre ellas se cita a las universidades, la seguridad social, las representaciones estamentales, cámaras de comercio, etc.

Finalmente, existiría una "periferia externa”. Este es el ámbito propio de la sociedad civil, como infraestructura sobre la que se apoya un espacio de opinión pública. Esta última está constituida por las asociaciones especializadas en suscitar temas, en plantear exigencias políticas, en articular intereses o necesidades y en ejercer influencia sobre la formulación de los proyectos de ley y las distintas políticas públicas.

Para Habermas la clave radica en que la legitimidad de las decisiones que se toman en el centro, atravesando las “esclusas” de los procedimientos democráticos propios del Estado de derecho, dependen de la periferia. Especialmente el complejo parlamentario requiere apertura a los procesos de formación de la opinión y a la voluntad de la opinión pública. La administración estatal no controla la totalidad de las dinámicas decisionales, ya que su legitimidad requiere del control de los flujos de comunicación que parten desde la periferia, considerando el contexto comunicativo de todos los potencialmente afectados. Si no cumple este requisito el poder administrativo se autonomiza ilegítimamente frente al poder comunicativo generado democráticamente.

Este modelo supone un doble movimiento: el centro requiere que sus decisiones sean legitimadas por el mundo de la vida y a la vez la sociedad civil debe luchar por ejercer influencia ante el poder administrativo. El espacio de la opinión pública es entendido así como un lugar de enfrentamiento, en la que se dan momentos de crisis que abren "instantes de movilización” que pueden cambiar las relaciones de fuerza entre la sociedad civil y el sistema político, pero a la vez es un plano de potencial superación de esos mismos conflictos.

La sociedad civil actuaría en la espera pública política como un actor de contención y contrapoder del poder administrativo, al manifestar las exigencias propias del mundo de la vida. La condición de posibilidad para ello es garantizar que la opinión pública no sea instrumentalizada, por lo cual cabe resolver las condiciones normativas 
que permitan mantener esa permanente capacidad deliberativa. Este contexto garantizar un conjunto de derechos fundamentales para permitir que la sociedad civil ejerza la presión suficiente sobre los decisores relevantes del sistema político.

Habermas relaciona este proceso a la capacidad autorreferencial de las prácticas de la comunicación en la sociedad civil: “con sus programas están ejerciendo influencia -y ésta es su intención directa sobre el sistema político, pero a la vez, reflexivamente, también se trata para ellos de la estabilización y ampliación de la sociedad civil y del espacio de la opinión pública y de cerciorarse de su propia identidad y capacidad de acción"17 Se concibe así una sociedad civil con una doble capacidad comunicativa: ofensiva (visibilizadora de denuncias, demandas, interpretaciones, argumentos y propuestas) y defensiva (del propio espacio de opinión pública que contiene sus identidades colectivas)

La acción de la sociedad civil está limitada al ejercicio de la incidencia, pero excluye el ejercicio directo del poder político. Se trata de una opinión pública en la que los actores ejercen influencia, pero no hacen efectivos los reclamos que recogen. Las instituciones democráticas mantienen su rol en el procesamiento de las demandas y la producción legítima de derecho.

La democracia deliberativa, sin relegar ni sustituir a las instituciones representativas, opera como un punto de conexión reflexiva entre el espacio de la opinión pública en donde la sociedad civil expresa al mundo de la vida y la voluntad política que opera en el complejo de las instituciones políticas y parlamentarias propias de un Estado de derecho. El poder comunicativo de la sociedad civil sólo influye indirectamente en el sistema político institucionalizado. A su vez el derecho se convierte en un sistema de «esclusas» donde las deliberaciones públicas son canalizadas hacia la toma de decisiones administrativamente vinculantes, que cuentan con la aceptación de los miembros de la comunidad jurídica y democrática.

En esta lógica Habermas da a entender que el campo de la economía estaría fuera de este proceso deliberativo-decisional, ya que sería una esfera que se desarrollaría enteramente bajo la lógica instrumental. Sin embargo, la realidad es que la incidencia de la sociedad civil "habermasiana” en el campo económico también es posible, y de forma igualmente indirecta que ante el Estado. Es el caso del movimiento por el comercio justo y a favor de la economía solidaria. O las movilizaciones de denuncia de abusos ambientales o laborales de las empresas. Este tipo de experiencias han obligado a procesos de respuesta ante la opinión pública desde el campo económico por medio de compromisos públicos contenidos en instrumentos de rendición de cuentas tales como los propuestos por el Pacto Mundial de Naciones Unidas ${ }^{18}$ o el Global Report Iniciative $^{19}$. 


\section{La desobediencia civil como expresión del poder comunicativo}

Un punto de especial relevancia en la descripción que Habermas hace de la incidencia de la sociedad civil sobre la administración estatal radica en la trasgresión simbólica de las normas, exenta de violencia, como protesta contra decisiones vinculantes que siendo 'legales', son ilegítimas. Esta forma de desobediencia civil implica actos ilegales, pero públicos, por parte de los autores que hacen referencia a principios y que son esencialmente simbólicos, por medios no violentos, apelando a lo que Rawls llama "sentido de justicia” de la población. En esta perspectiva la sociedad civil "habermasiana”, al implicarse en prácticas de reivindicación de derechos, busca superar la tensión entre lo fáctico y válido.

Habermas considera que estos actos reivindican principios utópicos de las democracias constitucionales apelando a la idea de los derechos fundamentales o de la legitimidad democrática. Quienes desobedecen manifiestan así la capacidad de la sociedad civil de remitirse a si misma en casos de crisis, actualizando los contenidos normativos del Estado democrático y haciéndolos valer en contra de su la inercia sistémica ${ }^{20}$.

Se expresa así la autoreferencialidad de la formación de la voluntad política con los procesos informales de comunicación en el espacio público.

La justificación de la desobediencia civil se encuentra además “en una comprensión de la constitución como proyecto inacabado”. La desobediencia civil tiene su lugar en un sistema democrático, en la medida en que se mantiene lealtad constitucional, expresada en el carácter simbólico y pacífico de la protesta. Se reconoce de esta forma que el Estado de derecho es un proyecto necesitado de permanente revisión. En el reconocimiento y resguardo de la posibilidad de esta expresión de disidencia radica un indicador clave de la madurez de una democracia.

La desobediencia, al invocar los "principios utópicos de la democracia” vincula argumentos de carácter jurídico y moral y por lo tanto reafirma el vínculo entre sociedad civil y sociedad política "cuando las tentativas legales de la primera de ejercer influencia sobre la segunda han fracasado y también han quedado agotadas otras vías”21 Se busca así que las "esclusas" del Estado se mantengan abiertas impidiendo su manipulación o clausura desde el poder social.

\section{Conclusión: el asedio comunicativo a la fortaleza}

"El poder comunicativo es ejercido a modo de un asedio. Influye sobre las premisas de los procesos de deliberación y decisión del 
sistema político, pero sin intención de asaltarlo, y ello con el fin de hacer valer sus imperativos en el único lenguaje la fortaleza asediada entiende"22

En esta frase se sintetiza buena parte de la reflexión de Habermas sobre la incidencia política de la sociedad civil, entendida como esfera no estatal y no económica en la que se ejerce la acción comunicativa. Desde ese campo se "asedia" a la "fortaleza" del poder administrativo, sin intención de asalto. La frontera entre el poder administrativo y el poder comunicativo es clara y tajante. Lo que se busca es "elevar el volumen" de aquello que resuena en los ámbitos de la vida privada. El único lenguaje la fortaleza asediada entiende es un acervo de razones y argumentos, que aunque el poder administrativo analice mediante la razón instrumental, deberá considerar, ya que está constreñido por un marco jurídico propio de un Estado de derecho.

Esta concepción abre la sociedad civil a procesos en los que se disputa poder comunicativo. A través de la incidencia efectiva, la participación ciudadana va más allá del marco de los procesos electorales para involucrarse en procesos en los cuales pueda hacer valer sus intereses, necesariamente particulares. Esta forma de concebir las relaciones entre lo estatal y lo social supera la perspectiva que ha considerado al Estado como el único defensor de los intereses universales.

La argumentación de Habermas respecto a la capacidad de la sociedad civil para influir en el campo público-político permite tender un puente entre las concepciones de la democracia de raíz liberal y las de raíz republicana. La democracia deliberativa que perfila su propuesta da espacio a que la sociedad civil pueda ejercer un rol en la esfera pública sin ser descalificada como un campo de intereses dispersos y corporativos, ni tampoco reducida a una estrategia subalterna a las orientaciones del Estado. La incidencia política de la sociedad civil adquiere así plena legitimidad, desde su independencia y autonomía. De esta forma se contempla una ciudadanía capaz de ejercer un conjunto de acciones dirigidas a transformar las relaciones de poder, con el propósito de lograr cambios específicos que tengan en cuenta los intereses de todos los involucrados.

Estas iniciativas rescatan de la razón estratégica algunos elementos que hacen que se pueda hablar de ellas como procesos deliberados y sistemáticos que implican acciones intencionadas. En este aspecto la acción de la sociedad civil no se basa sólo en la legitimidad o justicia de sus objetivos. Presupone también una voluntad de argumentación y negociación por medio de acciones simultáneas en un plazo de tiempo concreto. Se instala así una agenda de cambios que pasan por propiciar la dimensión creativa de la democracia, basada en una «ética de la modernidad crítica», capaz de superar las antinomias entre representación y participación por medio de una democracia que reconozca el poder comunicativo de la sociedad civil. 
Polis, Revista de la Universidad Bolivariana, Volumen 11, Nº 32, 2012

\section{Notas}

${ }^{1}$ Principios de estambul para el trabajo de las OSC como actoras del desarrollo. 29 de Septiembre 2010. http://www.cso-effectiveness.org/IMG/pdf/principiosdeosc-estambul-final.pdf

${ }^{2}$ De Tocqueville, A. La Democracia en América.I, edición crítica de E. Nolla, Madrid, Aguilar, 1989, p. 187.

${ }^{3}$ Edwards, M. (2005) Sociedad Civil, Enciclopedia de la educación informal, www.infed.org / asociación / civil_society.htm .

${ }^{4}$ García Marza, D. (2008) Sociedad civil: una concepción radical. Recerca, revista de pensament i anàlisi, núm. 8. p. 36

${ }^{5}$ Ibid, p. 40.

${ }^{6}$ Ibid. 40.

${ }^{7}$ Hegel, G. W. F., 2000, Filosofía del derecho, Madrid, Biblioteca Nueva. p. 182

${ }^{8}$ García Marza, D. (2008) Sociedad civil: una concepción radical. Recerca, revista de pensament i anàlisi, núm. 8. p. 41

${ }^{9}$ Habermas, J. Facticidad y Validez, Trotta, Madrid, p. 447

${ }^{10}$ Habermas, J. "Tres modelos normativos de democracia" en "La inclusión del Otro". Paidós. Barcelona. 1999. p. 233.

${ }^{11}$ Arendt, H. (2005). La Condición Humana. Barcelona: Ediciones Paidós Surcos. p. 352.

${ }^{12}$ Berlín, I. Dos conceptos de libertad, en “Cuatro ensayos sobre la libertad”, Alianza, Madrid, 1988

${ }^{13}$ Ibid. p. 223

${ }^{14}$ Habermas, J. Facticidad y Validez, Trotta, Madrid, p. 440

${ }^{15}$ Ibid. p. 447

${ }^{16}$ Ibid.. pp. 439-440.

${ }^{17}$ Ibid., p. 450.

${ }^{18}$ Cfr: http://www.un.org/es/globalcompact/index.shtml

${ }^{19}$ Cfr: http://www.globalreporting.org/Home

${ }^{20}$ Ibid. 465

${ }^{21}$ ibid. 465.

${ }^{22}$ ibid. 612. 


\section{Bibliografía}

Biglieri, Paula (2004), “Sociedad civil, ciudadanía y representación: el debate de los clásicos de la modernidad”. Revista Mexicana de Ciencias Políticas y Sociale, año XLVII, núm. 191, mayo-agosto de 2004, México.

De Tocqueville, Alexis (1989), La Democracia en América. I, edición crítica de E. Nolla, Aguilar, Madrid.

Durango Álvarez, Gerardo (2010,) El concepto de los derechos fundamentales en la teoría habermasiana: de la acción comunicativa a facticidad y validez Rev. Derecho. [online].En./Junio 2010, no.33 [citado 22 June 2011], p.247-276. Disponible en Internet: <http://www.scielo.unal.edu.co/ scielo.php?script=sci_arttext\&pid=S0121-86972010000100011\&lng $=e n \& n r m=i s o>$. ISSN 0121-8697

Edwards, Michael (2009), Civil Society. Polity Press, Cambridge, UK.

Ídem (2005), Sociedad Civil, Enciclopedia de la educación informal, www.infed.org / asociación / civil_society.htm

Fascioli, Ana (2009), “El concepto de sociedad civil en J. Habermas”. Revista $A C T I O \mathrm{n}^{\circ} 11$ - noviembre 2009. [online].En./Junio 2010, no.33 [citado 22 June 2011], p.247-276. Disponible en Internet: http:// www.fhuce.edu.uy/public/actio/Textos/11/Fascioli11.pdf

Foro Abierto Sobre la Afectividad del Desarrollo de las Organizaciones de la Sociedad Civil (2011), Disponible en Internet en formato HTML en: http://www.cso-effectiveness.org

García Marza, Domingo (2008), “Sociedad civil: una concepción radical”. Recerca, revista de pensament i anàlisi, núm. 8.. pp. 27-46 Departamento de Filosofía y Sociología. Universitat Jaume I de Castellón.

Habermas, Jürgen (2008), Facticidad y Validez, Trotta, Trad. Manuel Jiménez Redondo, Madrid,.

Hegel, Georg Wilhelm Friedrich (2000), Filosofía del derecho, Biblioteca Nueva, Madrid

Recibido: 17.09.2011

Aceptado: 25.07.2012 